SAE Paper No. 2005-26-014

\title{
Secondary Emissions Risk Assessment of Diesel Particulate Traps for Heavy Duty Applications
}

\author{
N. V. Heeb, A. Ulrich and L. Emmenegger
} EMPA Swiss Federal Laboratories for Material Testing and Research, Switzerland

J. Czerwinski, A. Mayer and M. Wyser Swiss Agency for the Environment, Forests and Landscape, Switzerland

\author{
Reprinted from - \\ The Proceeding of \\ Symposium on International Automotive Technology \\ SIAT 2005 - SAE Conference \\ Held at ARAI, Pune \\ india \\ 19 - 22 January 2005
}

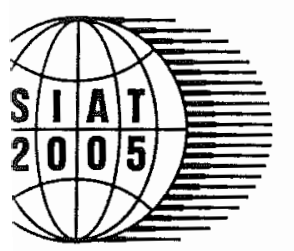
THE AUTOMOTIVE RESEARCH ASSOCIATION OF INDIA P.B. No. 832, Pune 411 004, INDIA. Tel. : 91 - 20 - 25437180/ 2 / 3 / 5
Fax : 91 - 20 - 25434190 www.araiindia.com




\title{
Secondary Emissions Risk Assessment of Diesel Particulate Traps for Heavy Duty Applications
}

\author{
N. V. Heeb, A. Ulrich and L. Emmenegger \\ EMPA Swiss Federal Laboratories for Material Testing and Research, Switzerland \\ J. Czerwinski, A. Mayer and M. Wyser \\ Swiss Agency for the Environment, Forests and Landscape, Switzerland
}

(C) 2005 The Automotive Research Association of India, Pune, India.

\begin{abstract}
Most particulate traps efficiently retain soot of diesel engine exhaust but the potential hazard to form secondary emissions has to be controlled. The Diesel Particle Filter (DPF) regeneration is mainly supported by metal additives or metallic coatings. Certain noble or transition metals can support the formation of toxic secondary emissions such as Dioxins, Polycyclic Aromatic Hydrocarbons (PAH), Nitro-PAH or other volatile components. Furthermore, particulate trap associated with additive metals can penetrate through the filter system or coating metals can be released from coated systems. The VERT test procedure was especially developed to assess the potential risks of a formation of secondary pollutants in the trap. The present study gives an overview to the VERT test procedure. Aspects of suitability of different fuel additives and coating metals will be discussed and examples of trap and additive induced formation of toxic secondary emissions will be presented.
\end{abstract}

\section{INTRODUCTION}

Particulate traps are very efficient to minimise soot emission of heavy duty diesel engines. Metal additives or metallic coatings can be used to enhance soot combustion in both, the engine and the particulate trap. Transition or noble metals used as fuel additives or catalytic coatings on the filter system decrease the soot ignition temperature to values that are obtained in most heavy duty applications. Diesel soot is a complex mixture of elemental carbon and organic compounds. Therefore, a loaded particle trap with added catalyst has to be considered as a chemical reactor with potential to form toxic secondary emissions such as Dioxins, PAH, Nitro-PAH or other volatile components. Furthermore, metal additives may penetrate the filter system or be released from its coating.
The VERT test procedure was developed in Europe to guarantee the efficiency and real-world suitability of particulate traps used on heavy-duty diesel engines. The VERT Secondary Emission Test (VSET), which is the main focus of this publication, was designed to avoid the potential risk of particulate traps for the formation of secondary pollutants. The VERT procedure is now mandatory for trap certification in Switzerland, Germany and Austria. Only particulate trap systems which passed this VERT test procedure are included in the VERT filter list [1] and officially recommended for retrofitting. Up to now, about 20 different particulate trap systems for heavy duty applications have been evaluated with respect to secondary emissions of toxic organic compounds as well as for trace metal penetration. In this study, aspects of suitability of different additive elements or coatings will be discussed. Moreover, correlations between specific metal species used as additive or coating and the potential formation risk of specific secondary pollutants have been investigated.

\section{EXPERIMENTAL}

VERT TEST PROCEDURE : The abbreviation VERT is a synonym for "Verminderung der Emissionen von RealDieselmotoren im Tunnelbau", which means reduction of real diesel engine emissions at tunnel construction sites. [1-3]. While tunnel construction was the main focus during the very first test development, the VERT procedure (Fig. 1) is now applied in a more general way to diesel particulate traps for other heavy duty applications and even to private traffic diesel vehicles. The VSET, is designed to identify traces of unwanted toxic secondary emissions. Hence, the test must fulfil the following conditions:

- Be representative for typical operational deployment of the DPF system

- Contain worst case conditions in terms of the formation of secondary toxic emissions 
- Ensure a representative sampling for the analysis of trace and ultratrace compounds

- Cover all possible DPF operation conditions, including loading and regeneration

- Include adequate sampling procedures for trace analysis of particulates, metals and organic compounds
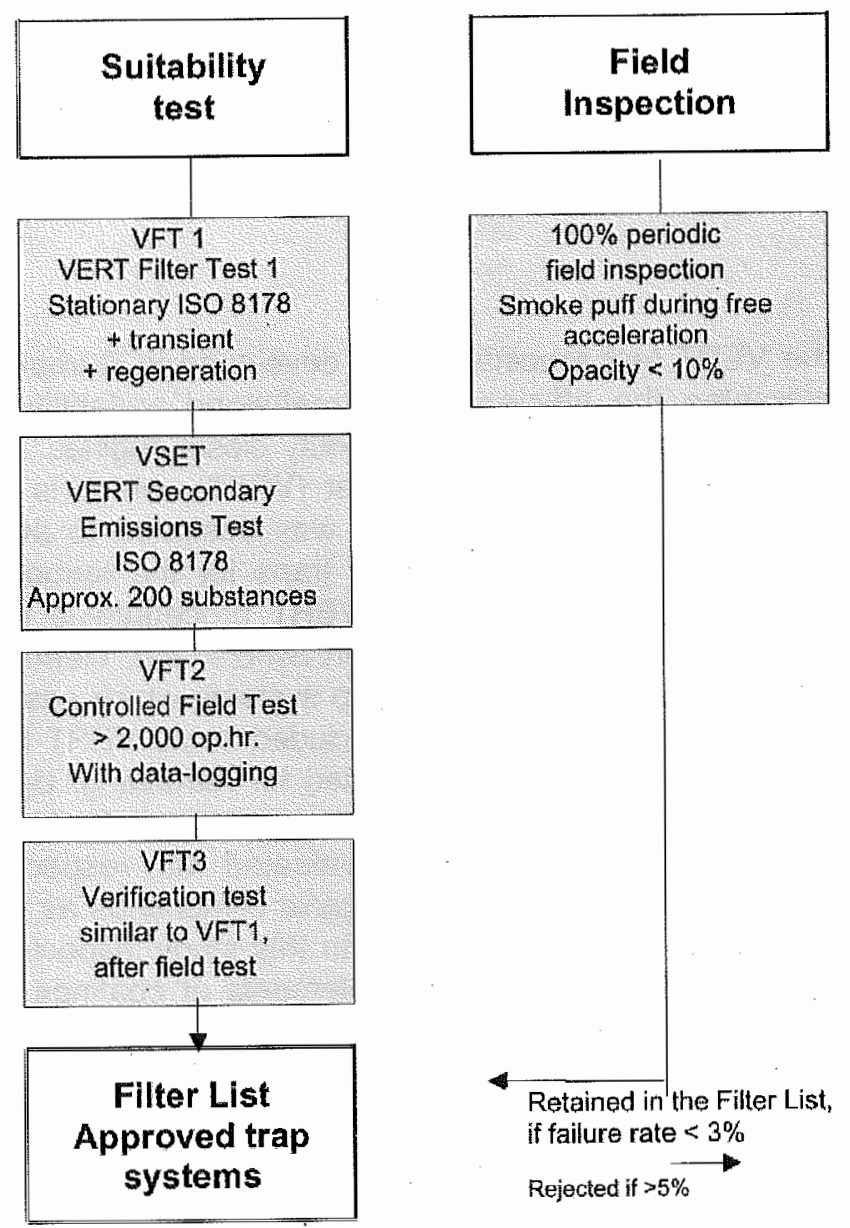

Figure 1 : VERT Suitability Test

VERT TEST CONDITIONS : Fig. 2 shows ISO 8178/4 C1 cycle which is driven two times in sequence to provide sufficient sampling time for inorganic analysis (200 $\mathrm{min})$ and four times $(400 \mathrm{~min}$ ) for appropriate sampling for organic analysis. The cycle is an industrywide consensus considered as representative for common operation conditions of construction site machinery. It ensures that all characteristic conditions for the formation and emission of toxic substances are simulated during the VERT test. This is especially important for the temperature, which covers a wide range from idle to full load.

The cycle covers both, the accumulation and the regeneration phase during which catalytic soot combustion takes place.

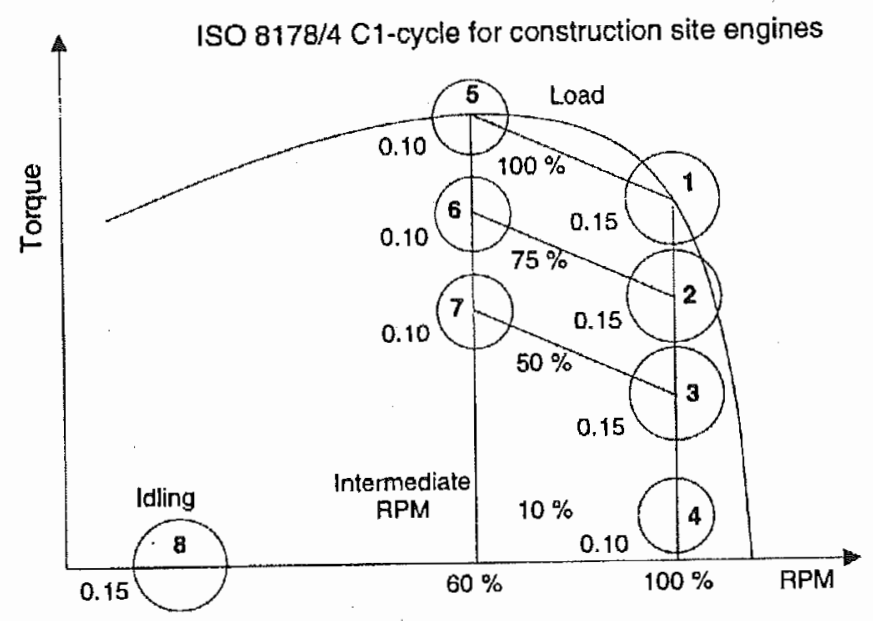

Figure 2 : Test Cycle for VSET Test According to ISO $8178 / 4 \mathrm{C} 1$

VERT TEST EQUIPMENT : The test described here were performed either at the University of Applied Sciences in Biel (FH Biel) or at the Swiss Federal Laboratories for Material Testing and Research (EMPA). Characteristics of the engines used are given in Table-l. The engines were run with diesel fuel according to EN SN 590. As particle traps require diesel with low sulphur content, the reference diesel was always a low sulphur diesel. The actual state of the art diesel fuel for VERT testing has sulphur content below $50 \mu \mathrm{g} / \mathrm{g}$.

\begin{tabular}{|l|l|l|}
\hline Sampling Site & FH Biel & EMPA \\
\hline Manufacturer & Liebherr & Liebherr \\
\hline Engine type & Liebherr 914 T & Liebherr 924 TI \\
\hline $\begin{array}{l}\text { Volume } \\
\text { Displacement, } l\end{array}$ & 6.11 & 6.6 \\
\hline $\begin{array}{l}\text { Rated Speed, } \\
\text { r/min }\end{array}$ & 2,000 & 2,000 \\
\hline $\begin{array}{l}\text { Rated power, } \\
\text { kW }\end{array}$ & 105 & 143 \\
\hline $\begin{array}{l}\text { Supercharging: } \\
\text { varbocharger with }\end{array}$ & $\begin{array}{l}\text { Turbocharger with } \\
\text { air intercooler and } \\
\text { direct injection }\end{array}$ \\
\hline
\end{tabular}

Table - I : Test Engines Used for VERT Tests

An overview of the main sampling locations and analytical techniques used during the secondary emission test (VSET) is given in Fig. 3.

SAMPLING : Depending on the DPF system, three to five test configurations are required. While all five configurations given below are tested for fuel additive supported DPF systems, for coated systems two configurations can be omitted. $M$ is a synonym for a specific additive metal and will be replaced in the 
Symposium on International Automotive Technology 2005

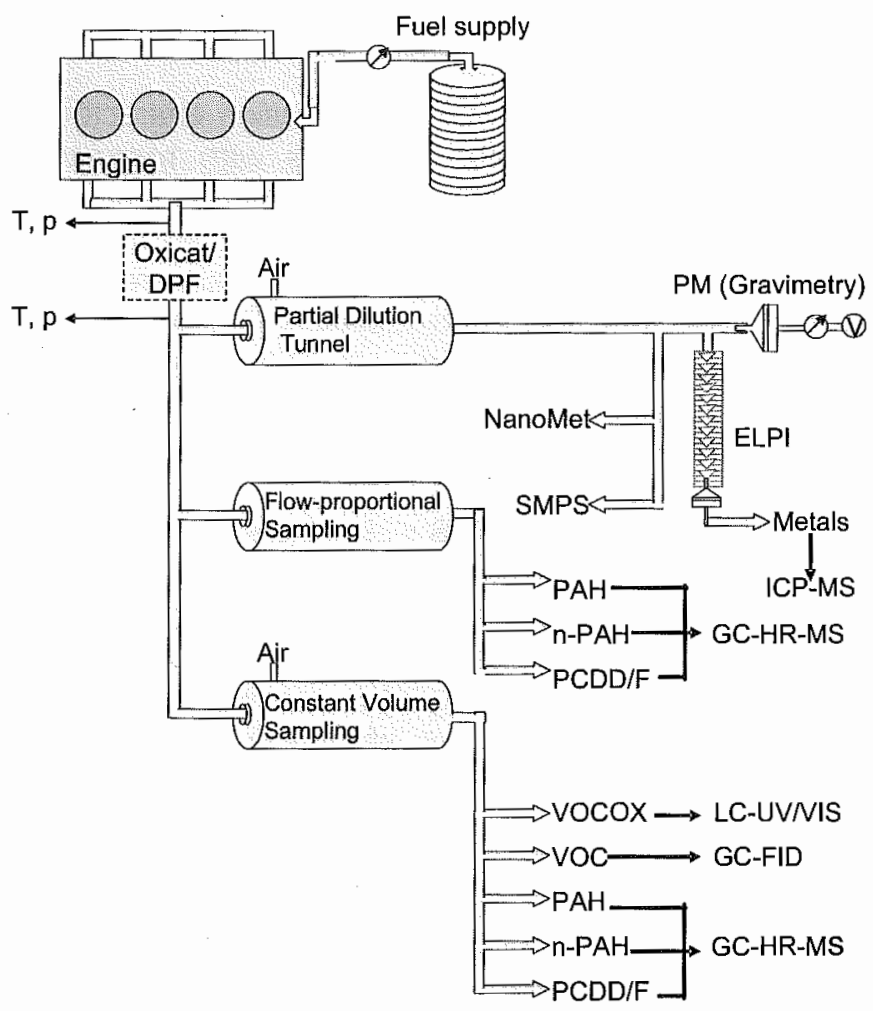

Figure 3 : Schematic of Sampling and Analytical Techniques in VERT Secondary Emissions Test (VSET)

following graphs by synonyms for specific elements such as $\mathrm{K}$ for copper, $\mathrm{C}$ for cerium, $\mathrm{E}$ for iron and $\mathrm{R}$ for Reference Diesel

RO : Engine driven with reference diesel without fuel additives and without particle trap

MO : engine driven with metal added diesel without particle trap

MF : Engine driven with metal added diesel with particle trap

HMO : Engine driven with metal and chlorine added diesel without particle trap

HMF : Engine driven with metal and chlorine added diesel with particle trap

Table-Il summarizes the parameters required according to the current VERT test regulation [4-5]. The list covers besides regulated pollutants also potential unwanted toxic secondary emissions of serious health risk.

ORGANIC ANALYSIS: For the analysis of organic traces, such as PCDD/F or PAH, it is necessary to sample large amounts of raw gas [6]. To yield a representative sample, its volume has to be proportional to the total raw gas flow at any given time of the test cycle. This was achieved by pumping a partial flow of the exhaust out of the $100 \mathrm{~mm}$ ID tubing directly after

\begin{tabular}{|c|c|c|}
\hline Parameter & Sampling type & Analytical method \\
\hline Opacity & $\begin{array}{l}\text { Directly from } \\
\text { exhaust gas }\end{array}$ & $\begin{array}{l}\text { Method of free } \\
\text { acceleration } \\
\text { according METAS- } \\
\text { instrument norm, } \\
\text { SAE J } 1667\end{array}$ \\
\hline EC mass & $\begin{array}{l}\text { Partial flow or full } \\
\text { flow dilution tunnel }\end{array}$ & $\begin{array}{l}\text { Coulometry } \\
\text { according to } \\
\text { VDI } 2465\end{array}$ \\
\hline PM mass & Partial flow dilution & $\begin{array}{l}\text { Filter gravimetry } \\
\text { according } \\
\text { ISO } 8178\end{array}$ \\
\hline $\begin{array}{l}\text { PM size } \\
\text { distribution }\end{array}$ & Partial flow dilution & ELPI + SMPS \\
\hline $\begin{array}{l}\text { Particle number } \\
(10-300 \mathrm{~nm})\end{array}$ & $\begin{array}{l}\text { Partial flow dilution } \\
\text { or full flow or } \\
\text { directly from } \\
\text { exhaust gas }\end{array}$ & $\begin{array}{l}\text { Thermodilution } \\
\text { and SMPS }\end{array}$ \\
\hline Particle surface & $\begin{array}{l}\text { Partial flow dilution } \\
\text { or full flow or } \\
\text { directly from } \\
\text { exhaust gas }\end{array}$ & $\begin{array}{l}\text { NanoMet including } \\
\text { thermodiluter }\end{array}$ \\
\hline $\mathrm{CO}$ & $\begin{array}{l}\text { Condensation } \\
\text { from exhaust gas }\end{array}$ & NDIR \\
\hline $\mathrm{HC}$ & $\begin{array}{l}\text { Flow proportional } \\
\text { sampling from raw } \\
\text { exhaust gas }\end{array}$ & FID \\
\hline $\begin{array}{l}\text { NOx } \\
\text { NO2/NOx }\end{array}$ & $\begin{array}{l}\text { Heated sampling } \\
\text { line and } \\
\text { permeation dryer } \\
\text { from raw exhaust } \\
\text { gas }\end{array}$ & $\begin{array}{l}\text { CLD with } \\
\text { converter }\end{array}$ \\
\hline $\begin{array}{l}\text { Metals } \\
\text { (PM-bonded) }\end{array}$ & $\begin{array}{l}\text { Flow proportional } \\
\text { dilution, ELPI }\end{array}$ & ICP-MS \\
\hline $\mathrm{PCDD} / \mathrm{F}$ & $\begin{array}{l}\text { Flow proportional } \\
\text { from raw exhaust } \\
\text { gas, sampling train }\end{array}$ & GC-HRMS \\
\hline PAH & $\begin{array}{l}\text { Flow proportional } \\
\text { from raw exhaust } \\
\text { gas, sampling train }\end{array}$ & $\begin{array}{l}\text { GC-HRMS } \\
\text { LC-UV / } \\
\text { Fluorescence }\end{array}$ \\
\hline Nitro-PAH & $\begin{array}{l}\text { Flow proportional } \\
\text { from raw exhaust } \\
\text { gas, sampling train }\end{array}$ & GC-HRMS \\
\hline VOC & $\begin{array}{l}\text { CVS sampling } \\
\text { from diluted } \\
\text { exhaust }\end{array}$ & GC-FID \\
\hline $\begin{array}{l}\text { Aldehydes/ } \\
\text { Ketons (VOCOX) }\end{array}$ & $\begin{array}{l}\text { CVS sampling } \\
\text { from diluted } \\
\text { exhaust, } \\
\text { chemisorption }\end{array}$ & LC-UV/VIS \\
\hline
\end{tabular}

Table - II : Parameters Tested in VERT Static Test Including Sampling and Analytical Method

the engine or after the particulate trap. The raw exhaust flux was determined based on continuous measurements of gas velocity and temperature using a Pitot tube and a K-type thermo-element. The sample flow was 
continuously measured by a specially designed Venturi and the frequency controlled pump adjusted accordingly by a dedicated software. Sampling was done by condensation and adsorption on XAD-2 in a condensation setup adapted from EN 1948-1. The total sample volume was about $10 \mathrm{Nm}^{3}$.

INORGANIC ANALYSIS : The VERT test procedure combines the control of a potential penetration risk of the additive elements supporting DPF regeneration. Additives are usually added in form of organo-metallic components or in form of colloidal oxides. Coated particle filter systems have to be controlled for a potential release of the coating metals. Therefore the particulate emissions are sampled size classified from the partial dilution tunnel using an Electrical Low Pressure Impactor (ELPI) with 12 stages for a size classification in the range of $30 \mathrm{~nm}$ to $10 \mu \mathrm{m}$ and an additional downstream backup filter to collect particles $<30 \mathrm{~nm}$.

All filter samples are digested in a MLS 1200 Mega High Performance Microwave Digestion Unit upgraded with temperature control unit. To achieve the required low detection limits, only ultra pure quality acids and highpurity water (18.2 M $\Omega \mathrm{cm}$ ), prepared by a Milli-Q Gradient A10 system are used for sample and standard preparation. Standards are prepared from single and multi-element standards in ICP-quality. A specific digestion procedure was especially optimised to achieve best detection limits [7-10].

Depending on the elements of interest, the aqueous digestion solutions are determined using a quadrupoleICP-MS ELAN 6000 or a magnetic sector field ICP-MS ELEMENT II, both operated under standard hot plasma conditions. The instrument detection limits of the ICP. MS are for most of the elements in the $\mathrm{ng} / l$ range.

The dosing of additive elements is also controlled. Sulphur and chlorine are directly determined in undiluted samples using a PW-1400 Wavelength Dispersive X-ray Fluorescence Spectrometer (WD-XRF) with typical detection limits of $1-2 \mu \mathrm{g} / \mathrm{g}$. Many elements can be determined directly in the diesel samples after dilution with xylene using an ICP-OES if oil-based calibration standards such as from Conostan are available. For the quantification of other elements the diesel samples have to be digested.

Further details about optimization of the metal sampling as well as development and optimization of the digestion procedure and analysis methods can be found in [7-10].

\section{RESULTS AND DISCUSSION}

As an example of the VSET, the emission characteristic of 4 sintered metal filter systems with respect to regulated and toxic organic compounds are discussed below. One sintered metal filter was operated with reference diesel and no additives. Three sintered metal filters (SHW) were run in combination with iron, cerium, and copper-based fuel additives. The additives were diluted to iron-, cerium- and copper-levels of 37, 64 and $56 \mu \mathrm{g} / \mathrm{g}$, respectively.

REGULATED POLLUTANTS : In all test configurations, the examined Euro-2 diesel engine (924 TI, 6.6 I) fulfilled the valid EU off-road limits for construction engines (stage 1) with limitations for $\mathrm{CO}, \mathrm{THC}, \mathrm{NOx}$ and PM of $5.0,1.3,9.2$ and $0.54 \mathrm{~g} / \mathrm{kWh}$, respectively. Figs. 4 to 7 represent the conversion efficiencies of the 4 traps for $\mathrm{THC}, \mathrm{PM}, \mathrm{NOx}$, and $\mathrm{CO}$.

As shown in Fig. 4, THC emissions are reduced by 25$49 \%$ when applying a trap in all tested configurations. Conversion efficiencies of $95-96 \%$ were obtained for particulate matter, which is shown in Fig. 5. As reported earlier, even higher filtration efficiencies above $98.6 \%$ are obtained for particulate number in the size range of 20 $300 \mathrm{~nm}$ [11]. These findings indicate that all investigated traps efficiently reduced particulate matter independent of the fuel additive used.

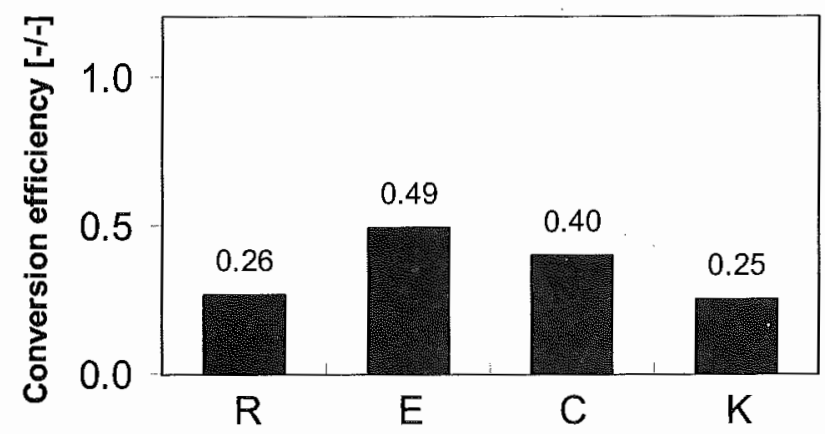

Figure 4 : THC Conversion Efficiency of Sintered Metal Filters with Reference Diesel (R), Iron- (E), Cerium-(C) and Copper- (K)Additivated Fuel

No significant effects of the applied traps were noticed for NOx emissions (Fig. 6) but as shown in Fig. $7 \mathrm{CO}$ conversion efficiency was negative for all 4 trap applications. This indicates that $\mathrm{CO}$ emissions increase by $15-45 \%$ due to the applied trap. It is unclear whether additional $\mathrm{CO}$ is formed via a trap-induced partial combustion of soot and adsorbed hydrocarbons, or if the 
increased $\mathrm{CO}$ emissions are the result of changed engine parameters, e.g. increasing exhaust gas back pressure.

It can be concluded that (i) an efficient filtration of particulate matter occurred, (ii) hydrocarbons were retained in all 4 investigated trap systems, (iii) the traps had no effects on nitrogen oxide levels and (iv) based on increased CO emissions a trap-induced soot combustion can be postulated.

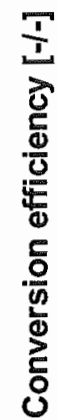
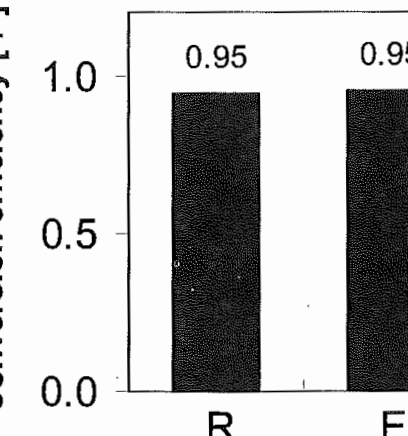

$\mathrm{R}$

$E$

K

Figure 5 : PM Conversion Efficiency

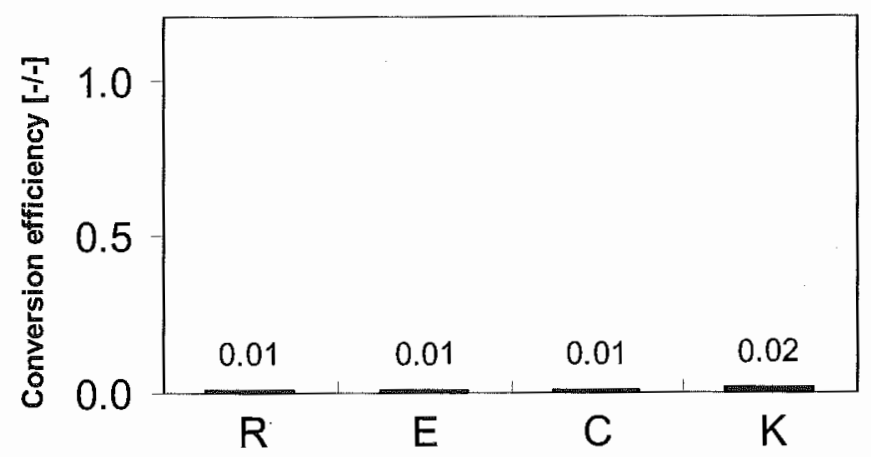

Figure 6 : NOx Conversion Efficiency

TOXIC ORGANIC TRACE COMPOUNDS : Given the pronounced chemical transformation reactions observed for the regulated pollutants, it is of importance to also study effects of such combustion conditions on the emissions of hazardous compounds present at trace-and ultra-trace level. Therefore, the scope of the analysis was enlarged and the potential secondary emissions risks for toxic, carcinogenic or mutagenic compounds were investigated in detail.

Fig. 8 displays the chemical structures of the most relevant toxic organic trace compounds investigated in VSET. The focus is mainly on the carcinogenic compounds.

VOLATILE HYDROCARBONS : At trace level, hundreds of different hydrocarbons can be distinguished in diesel exhaust, all of them contributing to the THC signal. Four of them, having chemical structures given in Fig. 8, are

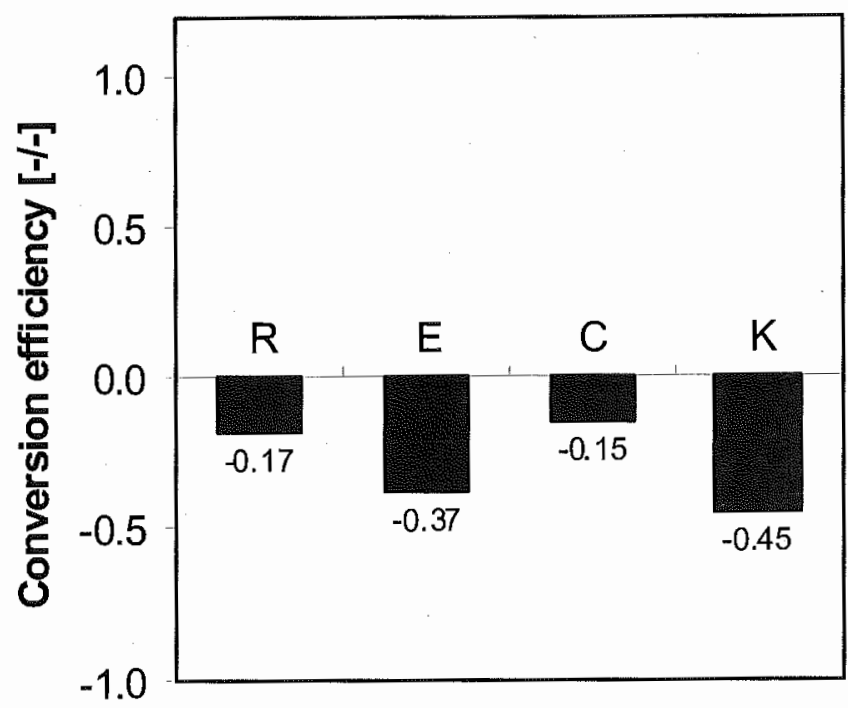

Figure 7 : $\mathrm{CO}$ conversion Efficiency

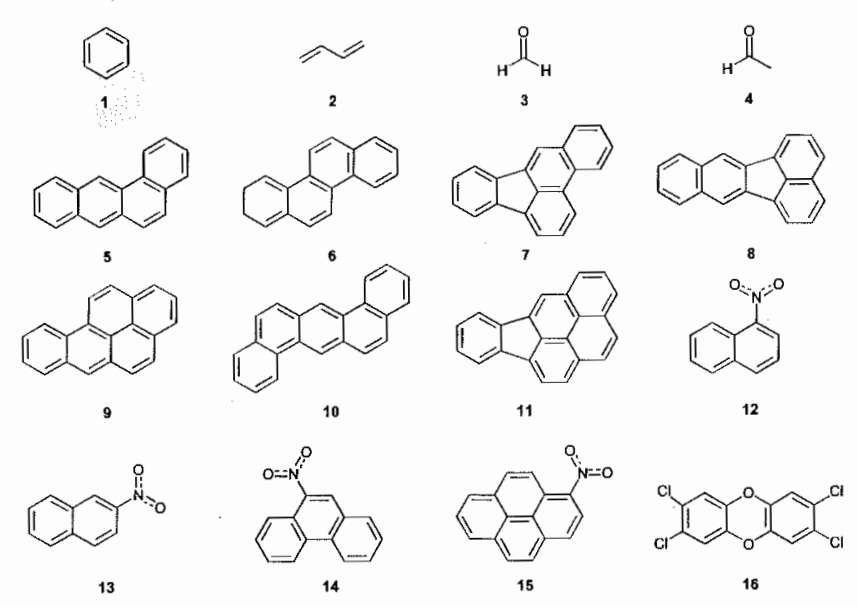<smiles>Clc1cc2c(cc1Cl)Oc1cc(Cl)c(Cl)c(Cl)c1Oc1cc(Cl)c(Cl)cc1O2</smiles>
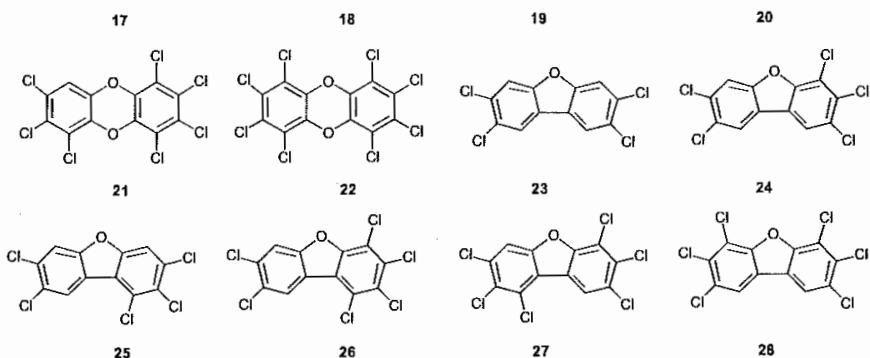

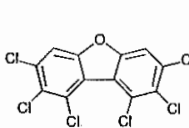

29

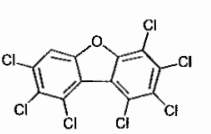

30

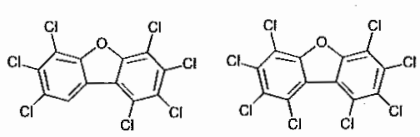

32
Figure 8 : Chemical Structures of Toxic Trace Compounds. Carcinogenic VOC (1-4), Carcinogenic PAH (5-11), Nitro- PAH (1215), Toxic PCDD (16-22) and Toxic PCDF (23-32) 
classified human carcinogens, Benzene (1), Butadiene (2), Formaldehyde (3) and Acetaldehyde (4).

Fig. 9 indicates that no net Benzene (1) conversion is occurring in the trap. On the opposite, negative conversion efficiencies were observed for all trap configurations indicating that Benzene is formed to some degree upon soot combustion. Similar findings were obtained for Butadiene (2) another volatile carcinogenic hydrocarbon (data not shown).

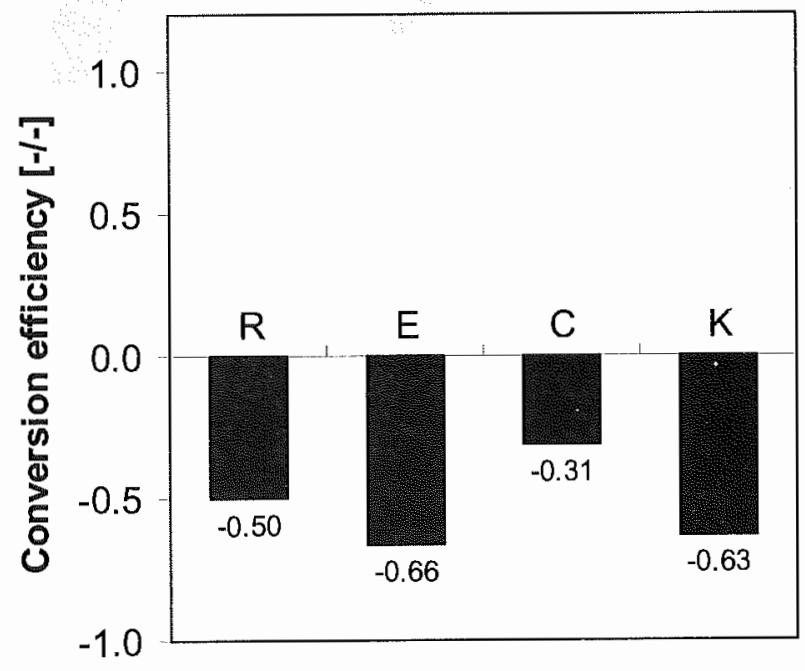

Figure 9 : Benzene Conversion Efficiency

This contrasts the findings of reduced overall hydrocarbon emissions (THC) as discussed above (Fig. 4). Benzene and Butadiene are highly volatile and therefore not adsorbed on the trap material or the diesel soot, whereas other higher boiling hydrocarbons such as the saturated hydrocarbons characteristic for diesel fuel $\left(\mathrm{C}_{x} \mathrm{H}_{2 x-2}, x>12\right)$ are less volatile and therefore efficiently retained in the trap.

Formaldehyde (3) and Acetaldehyde (4) are partially oxidised hydrocarbons classified as carcinogens too. Fig.10 shows that independent of the fuel, formaldehyde emissions are reduced to some degree in the traps. Since both aldehydes are volatile enough to penetrate the trap, the overall reduction is less efficient than for less volatile hydrocarbons.

POLYCYCLIC AROMATIC HYDROCARBONS : The analysis of polycyclic aromatic hydrocarbons was limited to 4- to 7-ring systems only. At room temperature, these $\mathrm{PAH}$ are mainly bound to particulates. Among these only the carcinogenic PAH refered in Fig. 8 Benzo(a) Anthracene (5), Chrysene (6), Benzo(b)Fluor- Anthene (7), Benzo(k)Fluoranthene (8), Benzo(a)Pyrene (9), Dibenzo (a,h)Anthracene (10) and Indeno(1,2,3- c,d) Pyrene (11) were investigated.

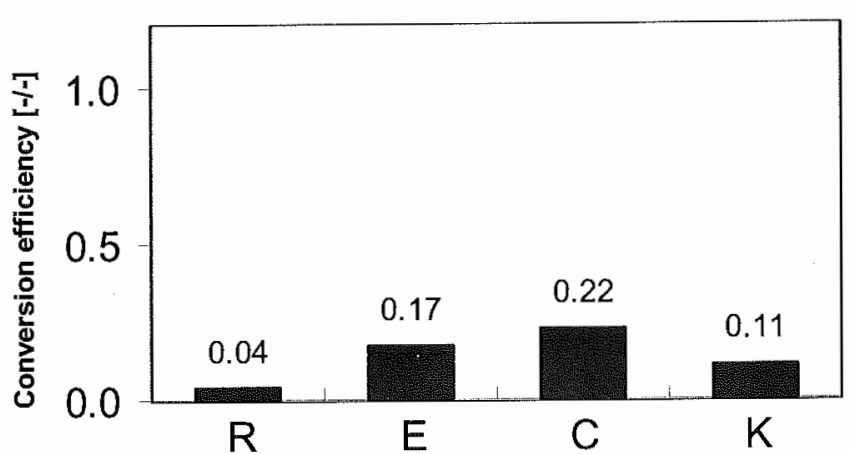

Figure 10: Formaldehyde Conversion Efficiency

Fig. 11 displays the conversion efficiency for the sum of these carcinogenic PAH during trap application. All 4 trap configurations clearly reduced the emissions of carcinogenic PAH by $28-91 \%$. Conversion efficiencies were even higher than those of the THC class of compounds, but lower than for soot as shown in Figs. 4 and 5 respectively.

These findings indicate that particulate traps significantly reduce the toxicity of diesel engine exhaust gas regarding carcinogenic $\mathrm{PAH}$.

\section{POLYCHLORINATED DIBENZODIOXINS/FURANS :} Compared to the regulated pollutants and to the individual hydrocarbons discussed so far, Poly- Chlorinated Dibenzo Dioxins / Furans (PCDD/F) are present only at ultra-trace levels $(10-12 \mathrm{~g})$. Of the 75 different PCDD- and of the 130 individual PCDF- congeners only those 17 isomers with chlorine atoms at positions $2,3,7$ and 8 are toxicologically relevant (Fig. 8). The overall toxicity of the PCDD/F-fraction (TEQ-sum) is therefore determined from the relative toxicity of the $2,3,7,8$-substitued congeners and their respective concentration. The most toxic congener, the 2,3,7,8- Tetrachlorodibenzodioxin (16), the so-called "Seveso-dioxin", is weighted with a factor

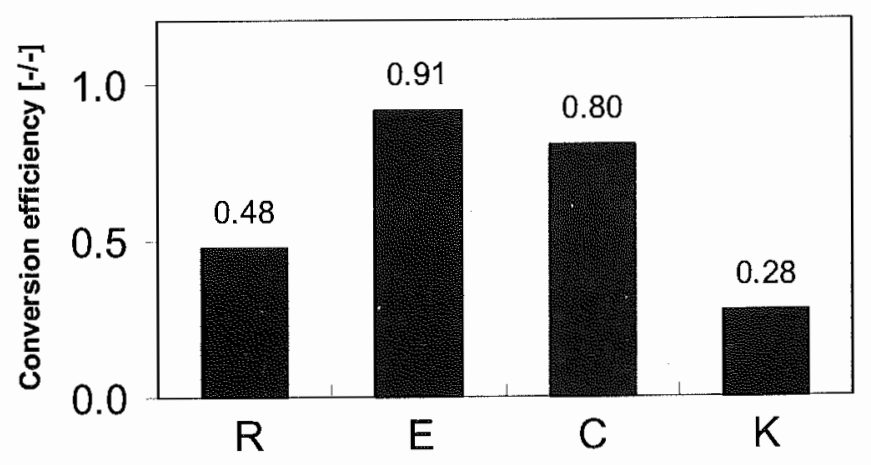

Figure 11 : Carcinogenic PAH Conversion Efficiency 
1, the least toxic Octochlorodibenzodioxin (22) with a toxicity equivalent factor of 0.001 .

Exhaust gas treatment in Municipal Waste Incinerators (MWI) can induce a new formation of Polychlorinated Dibenzo Dioxins / Furans. Especially during the filtration step a de-novo formation was observed in the critical temperature range of $260-440{ }^{\circ} \mathrm{C}$. Fig. 12 shows, that the examined particulate traps have been operated about $75-80 \%$ of the time in this critical temperature window. The filter material itself as well as the trapped diesel nano-particles offer a large surface for adsorption and therefore prolongate the residence time of potential $\mathrm{PCDD} / \mathrm{F}$ precursor molecules in the trap. It is known that the presence of copper in the chlorine-rich flue gas of waste incinerators has a catalytic effect on the PCDD/ $F$ formation [12].

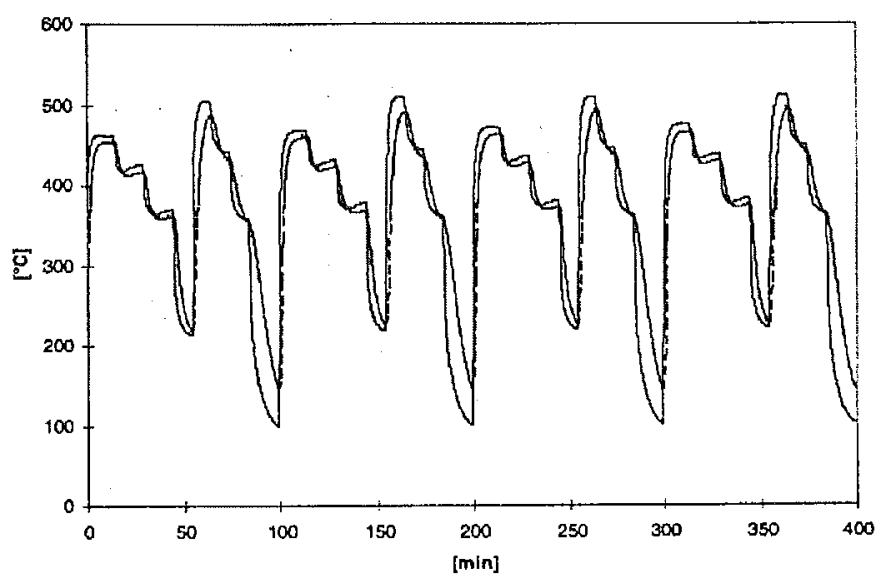

Figure 12 : Temperature Profiles Before and after a Sintered Metal Filter During Four Consecutive ISO $8178 / 4$ C1 Cycles

It can be concluded that all necessary conditions but one are given for an efficient de novo formation of $\mathrm{PCDD} / \mathrm{F}$ in a particulate trap. Residence time, temperature, precursor levels and - in case of copper additives - also catalysts are optimal for an efficient PCDD/F synthesis. Only the chlorine levels are expected to be considerably lower than in MWI flue gas.

Therefore, the potential chlorine intake was examined. In the urban air of Zürich several $\mu \mathrm{g} / \mathrm{Nm}^{3}$ of chlorinecontaining compounds, mostly chlorinated solvents, were present. Whereas no chlorine could be detected in the diesel fuel itself $(<5 \mu \mathrm{g} / \mathrm{g})$, about $160 \mu \mathrm{g} / \mathrm{g}$ chlorine was found in the applied lubricant oil. From these findings it can be concluded, that chlorine can accumulate in a particulate trap at $\mu \mathrm{g}$-levels, representing a sufficient source for PCDD/F-formation at the pg-level. Nevertheless, to investigate the potential risk of a trapinduced PCDD/F formation at worst case conditions the chlorine intake of the trap was increased via the application of chlorine-additivated diesel fuels.
Figs. 13 and 14 display the filter efficiency for PCDD/F (TEQ-sum) using commercial diesel fuel with no chlorine $(<5 \mu \mathrm{g} / \mathrm{g})$ and chlorine-additivated diesel $(H, X=10$, $100 \mu \mathrm{g} / \mathrm{g}$ ). The chlorine level was increased via mixing with an aliquot of 1,6-dichlorohexane.

As shown in Fig. 13, the application of the sintered metal filter had no negative effect on PCDD/F emissions when using reference fuel as well as the iron- and cerium-based regeneration additives. But the copperregenerated system clearly had a negative impact on the PCDD/F emissions. About 10 times more PCDD/F are emitted from the trap system than from the engine.

Even at increased chlorine levels as shown in Fig. 14, the trap itself as well as the iron- and cerium-regenerated

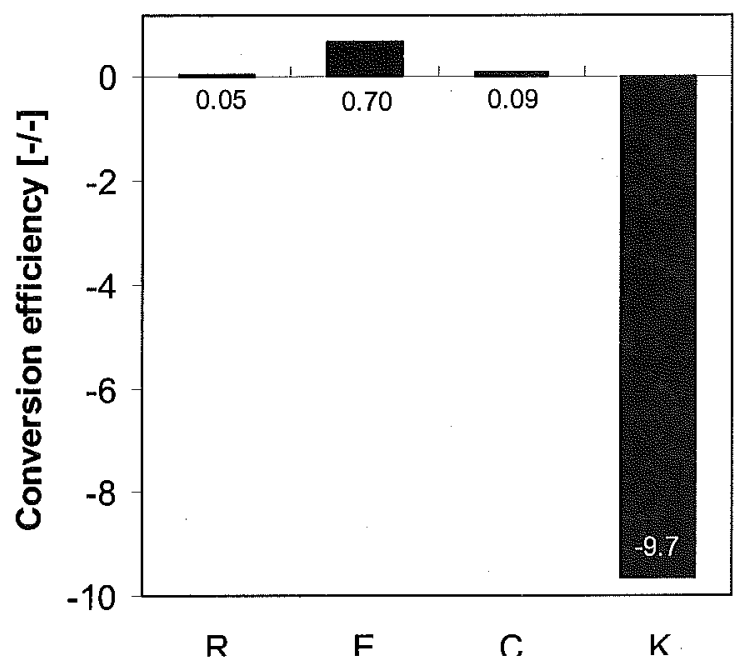

Figure 13 : PCDD/F (TEQ-sum) Conversion Efficiency

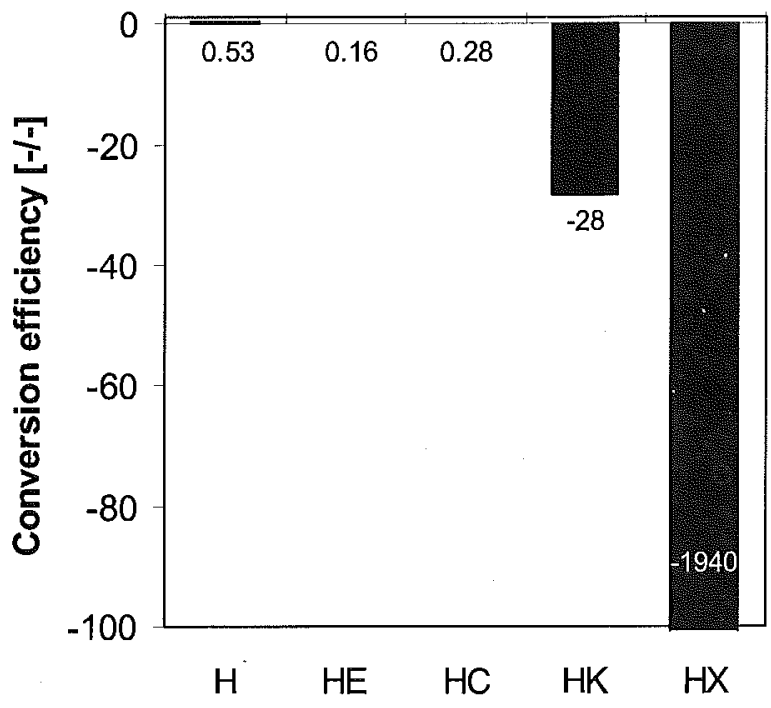

Figure 14 : PCDD/F (TEQ-sum) Conversion Efficiency of Sintcred Metal Filter with Chlorine $(H, X=10,100 \mu \mathrm{g} / \mathrm{g})$, Iron- $(\mathrm{E})$, Cerium- (C) and Copper- (K)-Additivated Fuel 
traps did not induce an increase of the PCDD/F emissions. In case of the copper-regenerated trap, PCDD/F emissions increased by about factors of 30 and 2000 when applying the chlorine-additivated fuels, respectively. These findings clearly prove that the presence of copper significantly increases the PCDD/Fformation potential of a particulate trap. This potential can be further increased with the presence of trace amounts of chlorine ( $\mu \mathrm{g}$-level) which can not be excluded at real world applications.

These findings also prove that particulate trap systems with different catalytic metals can promote very trapspecific chemical processes.

\section{EFFECTS OF FUEL-ADDITIVES AND CATALYTIC COATINGS ON METAL EMISSIONS AND PARTICLE} SIZE DISTRIBUTIONS : The additive must be well distributed in a stable mixture with the fuel. Usually the additive doses range between 10 and $50 \mu \mathrm{g} / \mathrm{g}$. The additives must mix perfectly with the diesel fuel and should be well distributed within each fuel micro-droplet during the combustion process. The stability of the additive-fuel mixture depends on the chemical form of the additive metal as well as on the fuel composition. Additives are usually added as organo metalliccompounds (e.g. iron) or in form of colloidal oxide (e.g. cerium) [13]. At first, single metal additives have been tested but mixtures of two additive metals become more common. According to current knowledge, the additives form catalytically active metal oxides during combustion and exit the combustion chamber as ultra-fine solid clusters in the nano-meter range.

Additives can change size distribution of the emitted particles[14-17]. It might also be assumed that the chemical form of an additive has a significant effect on the size distribution, especially if it is taken into account that additives are often applied in form of colloidal oxides. Fig. 15 gives an example of the particle size distribution of diesel soot generated with a non- and a cerium additivated fuel ( $35 \mu \mathrm{g} / \mathrm{g}$ cerium) by means of particulate number. The cerium additive seems to induce a shift to smaller particle sizes and shows a bimodal distribution in comparison to the non-additivated fuel.

Fig. 16 displays the particle size distribution of a copper/ iron additivated and a non-additivated reference fuel by means of metal content. The size classified metal content increased from less than $0.05 \mu \mathrm{g} /$ filter for 10 $\mu \mathrm{m}$ particles to $1.6 \mu \mathrm{g} /$ filter for $0.1 \mu \mathrm{m}$ particles. $A$ comparison of this pattern with one of the reference diesel soot supports the above given hypothesis. The additivated diesel shows a bimodal distribution with a significant peak at smaller particle size whereas the nonadditivated diesel shows a flat distribution.
Table-III shows an example of a VERT tested DPF system operated with a cerium or iron fuel additive. The filter efficiency for particulate matter was determined to $98.2 \%$. The additive retaining efficiency, calculated based on the total amount of applied additive and on the cerium emissions found with the trap, can be amounted to $99.9 \%$. Therefore, the penetration for this specific system was rather low. However, the amount of cerium found in the test without DPF was also significantly lower than the originally dosed additive quantity. It can be assumed that the additive might be deposited in the system. A larger difference was also found in several tests, whereas this example showed a relatively huge discrepancy. A possible reason might be an insufficient stability of the additive-fuel mixture or additive deposition processes in the engine itself.

The degree of penetration probably depends on pore size of the DPF and the chemical form of the additive. The metal penetration through metal regenerated DPF systems is usually higher than metal release of new,

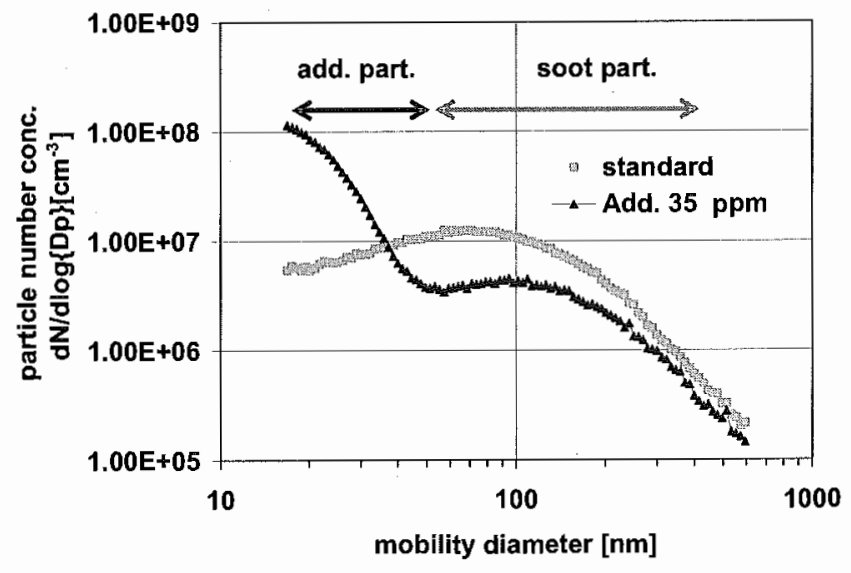

Figure 15 : Particle Dize Distribution of Diesel Emissions with and without Cerium Additivated Fuel [14]

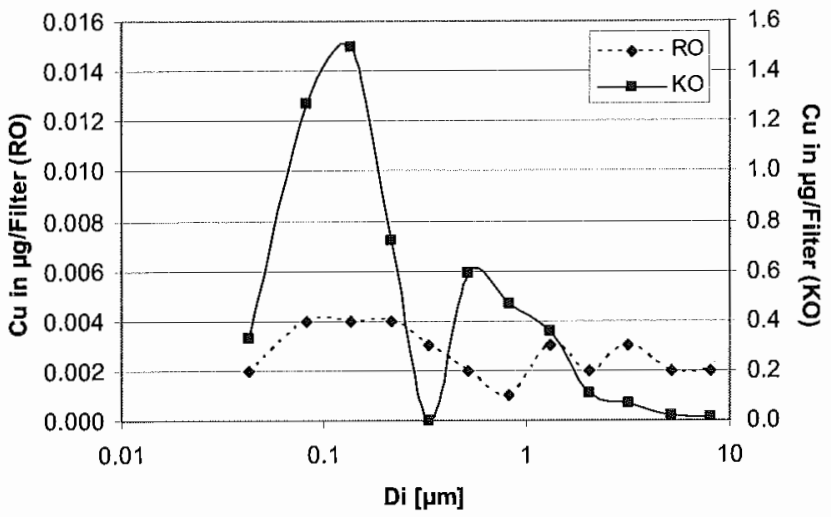

Figure 16 : Size Classified Copper Content in Diesel Soot for a $\mathrm{Cu} / \mathrm{Fe}$-Additivated Fuel $(\mathrm{KO})$ and an Additive-Free Reference Diesel (RO) 


\begin{tabular}{|l|l|}
\hline Additive Metal & Cerium \\
\hline Dosed Additive amount, mg & 473 \\
\hline PM ELPI without DPF, g & 2.05 \\
\hline PM ELPI with DPF, g & 0.04 \\
\hline Ce/PM in emission without DPF, mg & 15.4 \\
\hline Ce/PM in emission with DPF, mg & 0.3 \\
\hline
\end{tabular}

Table - III : Example of a VERT Tested DPF System Operated with a Cerium or Iron Fuel Additive

additive-free systems which operate with catalytic coatings. However, a release of the coating metals might increase with aging of the DPF. Therefore, a long-term monitoring of DPF systems in use is an urgent need to assess the hazard of secondary emissions of aged particulate trap systems.

\section{OUTLOOK}

Current metal sampling technique with ELPI covers only particulate bounded metals. A flow proportional sampling directly from the raw gas can also enable to determine non-particulate bonded or volatile metals [18].

A further investigation of long-term stability of additivefuel mixtures is necessary to guarantee stable solutions for general use. A clarification of the influence of additive form, fuel composition and other effects on the mixture stability is needed.

Specific changes of aged particulate trap systems might result in an increase of toxic secondary emissions. Therefore a long-term monitoring is desirable.

Secondary emissions during DPF accumulation and regeneration modes should be DPF distinguished and weighted according to the frequency of occurrence.

Secondary emissions risk assessment of DENOXsystems for heavy duty applications will be of future importance before the world wide application of this new exhaust gas treatment technology.

The influence and the contribution of the used lubrication oils to the formation of particulate matter should be investigated in a tracer study. First results will be published soon [19-21].

\section{CONCLUSION}

VERT is very valuable to discover insufficient systems which tend to form secondary emissions. Many tested filter systems gave promising results.
The VERT protocol, including the developed secondary emission test allows a comprehensive assessment of the benefits and risks of the current diesel particulate filter technologies.

The protocol was successfully applied up to 20 different trap systems so far, both to metal coated catalytic filters as well as to fuel-additive regenerated traps.

Among those traps two copper-regenerated systems had to be rejected because of a significant increase of polychlorinated dibenzodioxins or furans emissions.

In general, all trap systems clearly reduced the emissions of carcinogenic PAH and therefore had a positive effect on the toxicity of diesel exhaust gas.

\section{ACKNOWLEDGMENTS}

The authors gratefully acknowledge P. Honnegger (EMPA), R. Graf (EMPA), J.-L. Petermann (FH Biel), P. Comte (FH Biel) and T. Mosimann (Matter Engineering) for engine operation and exhaust gas sampling, A. Wichser (EMPA) and G. Müller (EMPA) for inorganic analysis and R. Haag (EMPA), E. Gujer (EMPA), P. Mattrel (EMPA), M. Kohler (EMPA), P. Schmid (EMPA) and M. Zennegg (EMPA) for organic analysis. We would also like to thank BUWAL (Swiss Agency for the Environment, Forests and Landscape, Bern) and SUVA (Swiss Accident Insurance Association) for financial an legislative support in VERT project as well as AKPF (Task force of particle filter system manufactures for support).

\section{REFERENCES}

1. Vert-Filtliste, "Geprüfte und Erprobte PartikelfilterSysteme Für Die Nachrüstung Von Dieselmotoren", BUWAL Bundesamt für Umwelt, Wald und Landschaft der Schweiz, Bern, 2004

2. http://www.akpf.org/pub/vert_sum_de.pdf., "Vert Verminderung Der Emissionen von RealDieselmotoren im Tunnelbau", Abschlussbericht, 1994-2000

3. Saefl, "Particulate Traps for Heavy Duty Vehicles", Environmental Documentation No. 130, Berne, 2000

4. SAE J 1667, "Snap Acceleration Smoke Test Procedure"

5. "Chemisch Analytische Bestimmung Des Elementaren Kohlenstoffs", VDI Norm 2465

6. Mohn, J., et al., "Time-resolved ammonia measurement in vehicle exhaust", Int. J. Environment and Pollution, Vol. 22 (3), pp. 342-356, 2004

7. Ulrich, A. and Wichser, A., "Metal Analysis of Diesel Vehicle Emissions", Proceedings of $6^{\text {th }}$ ETH Conference on Nano-particle Measurement, 2002 
8. Mayer, A., et al., "Retention of Fuel Borne Catalyst Particles by Diesel Particle Filter Systems", SAE paper 2003-01-0287

9. Ulrich, A. and Wichser, A., "Determination of Additive Metals in Fuel and Emissions of Diesel Vehicles", Proceedings of $7^{\text {th }}$ ETH Conference on Nano-particle Measurement, 2003

10. Ulrich, A., Wichser, A. and Anal. Bioanal. Chem., Vol. 377, pp. 71-81, 2003

11. Mayer, A., et al., "Reliability of DPF-Systems: Experience with 6000 Applications of the Swiss Retrofit Fleet", SAE paper 2004-01-0076

12. Hinton, W. S. and Lane, S. M., Chemosphere, Vol. 25, pp. 811-819, 1992

13. Macaudiere, P., et al., "Series Application of a Diesel Particulate Filter with a Ceria-based Nanoparticulate Fuel-borne Catalyst", Rhodia Technical Note, 2003

14. Mayer, A., et al., "Retention of Fuel Borne Catalyst Particles by Diesel Particle Filter Systems", Presentation on the SAE World Congress in Detroit, 2003

15. Matter, U. and Siegmann, K., J. Aerosol, Sci., Vol. 28 (1), pp. 551-552, 1997

16. Matter, U., et al., J. Aerosol Sci, Vol. 30 , pp. 471472, 1999

17. Skillaset, G., et al., "Combust Sci and Tech", 154, pp. 259-273, 2000

18. Ulrich, A., et al., "Sampling and Analysis of Trace Elements emitted by Diesel Vehicles", Proceedings of $8^{\text {th }}$ ETH Conference on Combustion Generated Nano-particles, 2004

19. Czerwinski, J., et al., "Particle Emissions of a TDIengine with Different Lube Oils", Proceedings of $8^{\text {th }}$ ETH Conference on Combustion Generated Nanoparticles, 2004

20. Czerwinski, J., et al., "Particle Emissions of a TDIEngine with Different Lubrication Oils", SAE paper 2005

21. Mueller, G., et al., "Contribution of Lubrication Oils to Particle Emissions of a TDI-Engine", J. Aerosol Sci, in Preparation

\section{ACRONYMS}

VERT Verminderung der Emissionen von RealDieselmotoren im Tunnelbau, which means reduction of real diesel engine emissions at tunnel construction sites = Swiss, German and Austrian task force to reduce emissions of heavy duty diesel engines

BUWAL Bundesamt für Umwelt, Wald und Landschaft, Bern = SAEFL Swiss Agency for the Environment, Forests and Landscape, Bern

SUVA Schweizerische Unfallversicherungsanstalt = Swiss Accident Insurance Association

EMPA Eidgenössische Materialprüf- und Forschungsanstalt $=$ Swiss Federal Laboratories for Material Testing and Research

AFHB Abgasprüfstelle der Fachhochschule, Biel $\mathrm{CH}$ = Laboratory for Exhaust Gas Control at the University of Applied Sciences, Biel-Bienne, Switzerland

\section{CONTACT}

Dr. Norbert Heeb, EMPA Swiss Federal Laboratories for Material Testing and Research, Überlandstrasse 129 , $\mathrm{CH}-8600 \mathrm{D}$ übendorf, Switzerland, Tel.: +411823 4257, E-mail : norbert.heeb@empa.ch. www.empa.ch. 